\title{
A correlation between bruxism and eccentric occlusal interferences
}

\author{
Ho-Sun Lee, Mi-Gyeong Kim, Soo-Yoon Jin, Hee-Jung Kim, Gyeing-je Lee* \\ Department of Prosthodontics, School of Dentistry, Chosun University, Gwangju, Republic of Korea
}

Purpose: The purpose of this study was to analyze correlation between bruxism and occlusal contacts on balancing side. Materials and Methods: The purpose of this study is to compare the difference of group function and balancing side occlusal contacts according to bruxism and sex, A total of 100 adults that aged 26-37 years (39 bruxers and 61 non-bruxers) were examined. The lateral excursion and balanced occlusal contacts were analyzed to determine the correlation with bruxism. The occlusal contacts were recorded by T-Scan system and articulating paper. Results: The group function was the highest in $61.5 \%$ of bruxers and $47.5 \%$ of non-bruxers. In comparison between males and females, group function was $58.9 \%$ in males and $37.0 \%$ in females. Occlusal contacts on non-working side occurred in 48 out of 100 patients. There were $51.2 \%$ of the cases in the bruxers and $46.0 \%$ in the non-bruxers. Statistically, there was no correlation between the bruxism and occlusal contacts on non-working side. There was no correlation between sex and balancing occlusal contacts. Conclusion: There was no significant correlation between bruxism and occlusal contacts on non-working side. The group function was the highest in bruxers when lateral excursion was occurred. (J Dent Rehabil Appl Sci 2018;34(4):253-61)

Key words: bruxism; eccentric occlusal interferences; canine guidance; group function; T-Scan system

\begin{abstract}
서론
이갈이(Bruxism)는 저작근의 수축으로 인해 발생하 는 이상기능의 하나로, 주간과 야간의 이 악물기와 이를 가는 비기능적 운동을 모두 포함한다. ${ }^{1}$ 미국보철학회에 서 발간한 The golssary of prosthodontics terms에서는 하악의 교합외상을 초래할 수 있는 비자발적인 규칙적 이거나 불규칙적인 이상 기능으로 가는 운동(gnashing, grinding) 또는 이 악물기(clenching)로 구성된 구강 습관 이라고 정의하였다. ${ }^{2}$

이갈이는 유병률이 연구마다 매우 상이하다. 이는 이 갈이의 기준 및 진단 등이 각 연구마다 모두 달랐기 때문 이다. 이갈이는 인구의 $85-95 \%$ 에서 가끔씩 이를 갈거

*Correspondence to: Gyeong-je Lee

Assistant Professor, Department of Prosthodontics, School of Dentistry, Chosun University, 303 Pilmun-daero, Dong-gu, Gwangju, 61452, Republic of Korea Tel: +82-62-220-3827, Fax: +82-62-232-7776, E-mail: lkj1998@chosun.ac.kr Received: July 6, 2018/Last Revision: August 5, 2018/Accepted: November 12, 2018
\end{abstract}

나 이 악물기가 있을 만큼 흔하며, 성인의 $5-8 \%$ 는 이갈 이 습관이 있다는 보고가 있다. ${ }^{3,4}$ Attanasio ${ }^{5}$ 는 이갈이는 40대까지 높은 빈도로 나타나다가 그 이후 줄어드는 양 상을 보인다고 했다. 성별에 따른 차이는 없는 것으로 나 타난다.

Clarke 등 ${ }^{6}$ 의 연구에서는 이갈이의 강도가 최대 이 악 물기의 $60-65 \%$ 정도 된다고 하였으나 Rugh 등 ${ }^{7}$ 은 이갈 이 환자의 $1 \%$ 에서는 이갈이의 강도가 최대 이 악물기 시 의 힘을 넘어가는 경우도 있다고 하였다. Cosme 등 ${ }^{8}$ 의 연 구에서 이갈이가 있는 사람의 최대 교합력은 $806 \pm 282$ $\mathrm{N}$, 이갈이가 없는 사람의 최대 교합력은 $859 \pm 304 \mathrm{~N}$ 으 로서 통계적으로 유의한 차이가 없다고 하였다.

이갈이로 인해 치아의 교모 및 치경부 미세파절, 치수

Copyright@ 2018 The Korean Academy of Stomatognathic Function and Occlusion. (c) It is identical to Creative Commons Non-Commercial License. 
염, 치수괴사, 보철물의 마모 및 파절, 치주조직 손상으로 인한 치아 동요도 증가, 지각과민증, 과백악질증(hypercementosis), 저작근의 비대 및 근육통, 두통, 측두하악장 애 등이 나타날 수 있다. ${ }^{9}$ 이 외에도 이갈이 소리로 인해 같이 자는 사람의 수면을 방해할 수 있기 때문에 배우자 와 가족관계, 그리고 단체생활에 장애가 되고 심할 경우 대인기피증상까지 나타날 수 있다. ${ }^{10}$

이갈이 원인에 대해서 명확히 밝혀진 것은 없지만 다양 한 원인이 복합적으로 작용하여 발생하는 것으로 알려져 있다. 과거의 연구에서 이갈이의 원인으로는 수면장애, 정서적 스트레스와 성격, 알코올과 약물의 남용, 교합 부 조화, 턱관절의 비가역적인 손상, 근막동통 등이 언급되 었다. ${ }^{11}$

비정상적인 교합과 이갈이의 상관관계에 과거의 다양 한 연구가 있었다. 1961년 Ramfjord ${ }^{12}$ 는 최후방 치아접 촉위와 교두감합위의 차이가 있거나 측방운동 시 비작업 측 접촉이 존재할 때 교합조정을 하고 난 뒤 이갈이가 줄 어듬을 확인하고 비정상적인 교합이 이갈이를 일으키는 주요 원인이라고 하였으나, Rugh 등 $^{13}$ 의 연구에서는 편위 적 교합접촉과 미끄러짐을 인위적으로 일으키는 crown 을 장착했을 경우 수면 시 교근의 활동도가 $90 \%$ 에서 유 의하게 감소가 나타났던 반대의 결과가 있었다. Kardachi 등 ${ }^{14}$ 의 연구에서도 교합간섭이 있는 이갈이 환자들에 게서 교합조정을 통해 교합간섭을 제거해도 이갈이 활성 도에 영향을 미치지 않았다. 반면 Safari 등 ${ }^{15}$ 의 연구에서 는 이갈이가 있는 30 명의 교합을 분석한 결과 이갈이와 균형측 교합접촉 간에 통계적으로 연관성이 있다는 결과 를 보고하였다. 이와 같이 이갈이와 교합간섭간의 관계 는 아직 명확한 결론이 내려지지 않았다.

아직 국내에서는 이갈이 환자를 대상으로 편심위 교합 접촉과 이갈이의 연관에 관한 연구사례가 없고, 일반인 을 대상으로 하는 교합접촉연구 또한 외국에서만 이루 어져 왔던 것이 사실이며, 국내에서의 연구는 부족하다. 따라서 본 실험에서는 디지털 교합분석장치 T-Scan II system (T-Scan system, TekScan Inc., Boston, USA) 장 비를 이용해 이갈이 및 비이갈이 대상군의 편심위 교합접 촉분석을 통하여 이갈이와 균형측 교합접촉간의 상관관 계에 대하여 알아보기로 하였다.

\section{연구 재료 및 방법}

\section{1. 연구 대상}

성별에 따른 이갈이 차이 및 측방유도 양상 차이를 분 석하기 위해 남녀로 구분하여 연구대상을 선정하였다. 조선대학교 치과병원에 내원한 환자 및 모집에 지원한 조선대학교 치의학전문대학원 학생으로서 26세에서 37 세 사이의 성인 남녀 100 명(남자 73명, 여자 27명)을 대상 으로 실험을 진행하였다. 이중 이갈이군은 39 명, 비이갈 이군은 61명 이었다(Table 1).

실험은 조선대학교 치과병원 임상시험 심사위원회 심 의를 거친 후(CUDHIRB-1608-035) 가이드라인에 따라 진행되었다. 실험 대상자 선정조건은 1) 제 3 대구치를 제 외한 치아의 상실이 2개 이상이 있거나, 2) 4 단위 이상 의 보철수복이 되어 있는 경우, 3) 위-식도 역류 질환이 있 는 경우, 4) 개방교합과 같은 심한 치성 부정교합 및 골격 성 부조화가 있는 경우는 제외하였다. ${ }^{15}$ 이갈이 진단은 미 국수면장애협회(American Sleep Disorders Association; $\mathrm{ASDA})$ 의 기준을 사용하여 이갈이 소리와 함께 비정상 적인 치아 교모, 아침 기상시의 턱관절의 불편감, 피로, 통증, 혹은 교근 비대 중 1 가지 이상이 있는 경우로 하였 다(Table 2). ${ }^{16}$

Table 1. Classification of each test group

\begin{tabular}{cccc}
\hline & Male & Female & Total \\
\hline Bruxism & 26 & 13 & 100 \\
Non Bruxism & 47 & 14 & \\
\hline
\end{tabular}

Table 2. Criteria for the diagnosis of sleep bruxism

\begin{tabular}{l} 
International classification of sleep disorders, 2005 \\
\hline The patient reports, or is aware of, tooth-grinding sounds \\
or tooth clenching during sleep \\
One of the following is present: \\
- Abnormal wear of the teeth \\
- Jaw discomfort, fatigue, or pain and jaw lock upon \\
awakening \\
- Masseter muscle hypertrophy upon voluntary forceful \\
clenching \\
The jaw muscle activity is not butter explained by another \\
current sleep disorder, medical or neurological sleep \\
medication use, or substance use disorder
\end{tabular}




\section{2. 연구 방법}

1) 이갈이 설문조사

설문조사지를 이용해 이갈이 진단을 위한 미국수면장 애학회의 이갈이 기준의 해당 사항에 대해 조사하고 임 상시험 참여 동의서에 동의를 받았다. 이갈이의 자각여 부, 주변 사람에게 들어서 알고 있는지 여부와 아침 기상 시 저작근의 피로감 및 통증, 턱이 벌어지지 않는 증상이 있는지 여부를 설문으로 조사하였다.

\section{2) 구강 내 검사}

구강 내 검사를 통해 치아의 마모도, 측방유도양상, 보 철물의 유무 상태, 치아의 동요도, 치아 상실 여부, 교정 치료 경험의 유무에 대해 검사하고 기록하였다. 측방유 도양상은 견치 유도 교합(Canine guidance), 군기능 교 합(Group function), 분류되지 않는 양상(Unclassifiable patterns)으로 구분하고 본 실험을 통해 이갈이와 비이갈 이군에서 군기능 교합이 보이는 정도를 측정하고자 하였 다. 견치 유도 교합은 상·하악 견치에서만 접촉이 이루어 지는 경우로 하였고, 군기능 교합은 작업측 견치에서 제 2소구치까지 2점 이상의 교합 접촉이 이루어지는 경우로 하였다. 그리고 견치 유도 교합과 군기능 교합에 속하지 않는 교합, 예를 들어 작업측의 교합접촉 없이 균형측 교 합접촉만 있거나 작업측 제 2 대구치의 한 점만 접촉되는 경우 등은 분류되지 않는 양상으로 구분하였다.

\section{3) 교합접촉의 기록}

구강 내 검사 후 디지털 교합분석장치를 이용해 최대 교두감합위, 좌측방 운동, 우측방 운동을 시행하여 교합 접촉을 검사하였다. 디지털 교합분석장치는 치아의 접 촉순서, 교합력의 변화. 교합 간섭점 등을 $2 \mathrm{D}, 3 \mathrm{D}$, timeforce graph를 통하여 가시적으로 분석할 수 있는 장점 이 있다. 측방운동 시 상악 중절치를 기준으로 최대교두 감합위에서 좌우로 $3 \mathrm{~mm}$ 까지 운동시켰다. 디지털 교합 분석장치 센서 두께로 인한 측정 오차를 줄이고 정확한 치아번호를 확인하기 위해 교합지를 사용하여 추가적으 로 교합접촉점을 확인하였다. 디지털 교합분석장치 검사 시에 간섭이 존재한다고 측정되었으나 측방운동 시 구치 부에서 교합지가 물리지 않을 경우 접촉이 존재하지 않 는 것으로 간주, 균형측 교합접촉이 없는 군으로 분류하 여 이갈이와 비이갈이군에서 균형측 교합접촉을 보이는 정도, 이갈이와 균형측 교합접촉간의 상관성을 밝히고자
하였다.

\section{3. 통계학적 분석}

SPSS Ver. 20.0 (IBM SPSS Statistics 20.0, SPSS Inc, Chicago, USA) 프로그램을 이용하여 통계처리 하였다. 이 갈이 유무와 편심위 유도 양상, 균형측 교합 접촉의 관계 및 성별에 따른 차이를 파악하기 위해 두 가지 이상의 질 적변수, 즉 범주형 변수의 상관관계를 분석하기 위한 통계 적 방법으로 Chi-square test $(P<.05)$ 를 시행하였다.

\section{결과}

측방유도검사 결과 이갈이군에서는 군기능 교합이 $61.5 \%$, 견치 유도 교합이 $12.8 \%$, 기타 $25.6 \%$ 로 나타났 고, 비이갈이군에서는 군기능 교합 $47.5 \%$, 견치 유도 교 합 $41.0 \%$, 기타 $11.5 \%$ 로 나타났다(Fig. 1). 이갈이군에 서 높은 비율로 군기능 교합이 나타났고, 비이갈이군은 군기능 교합과 견치 유도 교합이 비슷한 정도로 나타났 다. 통계적으로 이갈이가 있을 경우 군기능 교합이 나타 날 확률이 높다(Table 3).

성별에 따른 이갈이 유무는 남성 그룹은 $35.6 \%$, 여성 그룹은 $48.1 \%$ 로서 통계적으로 성별에 따른 이갈이 유무 의 차이는 없었다(Table 4).

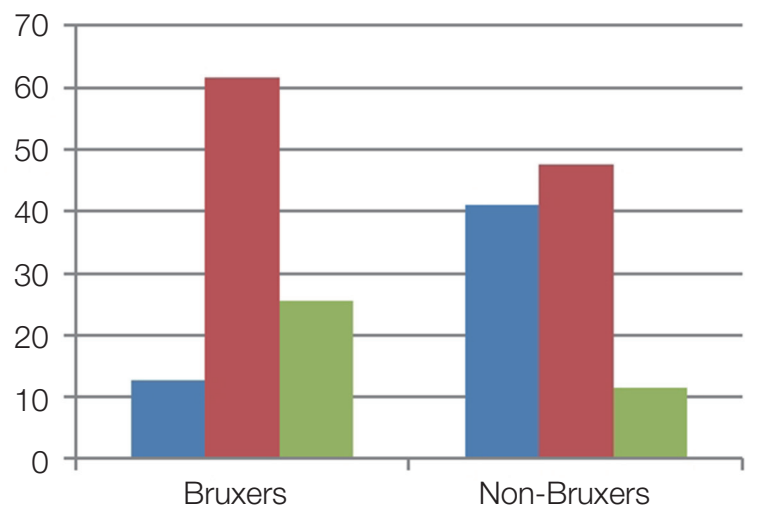

- Canine guidance

- Group function

- Unclassifiable patterns

Fig. 1. Comparison of bruxism between canine guidance \& group function. 
Table 3. Comparison of bruxism between canine guidance \& group function

\begin{tabular}{ccccc}
\hline & Canine guidance & Group function & Unclassifiable pattern & $\chi^{2}(P)$ \\
\hline Bruxer & $5(12.8 \%)$ & $24(61.5 \%)$ & $10(25.6 \%)$ & $9.977(0.007)^{\mathrm{a}}$ \\
Non-Bruxer & $25(41.0 \%)$ & $29(47.5 \%)$ & $7(11.5 \%)$ & \\
\hline
\end{tabular}

${ }^{a}$ Statistically significant difference $(P<0.05)($ Chi-square test $)$

Table 4. Comparison of bruxism between male \& female

\begin{tabular}{cccc}
\hline & Male & Female & $P$-value \\
\hline Bruxers & $26(35.6 \%)$ & $13(48.1 \%)$ & $0.254^{\mathrm{a}}$ \\
Non-Bruxers & $47(64.4 \%)$ & $14(51.9 \%)$ & \\
\hline
\end{tabular}

${ }^{a}$ Statistically significant difference $(P<0.05)($ Chi-square test)

Table 5. Balancing side contacts of bruxers \& non-bruxers

\begin{tabular}{ccccc}
\hline \multicolumn{2}{c}{ Bruxers $(\mathrm{N}=39)$} & \multicolumn{2}{c}{ Non-Bruxers $(\mathrm{N}=61)$} \\
\multicolumn{2}{c}{ Balancing side occlusal contacts } & \multicolumn{2}{c}{ Balancing side occlusal contacts } & No \\
Yes & No & Yes & $33(54.0 \%)$ & $0.148^{\mathrm{a}}$ \\
\hline $20(51.2 \%)$ & $19(48.8 \%)$ & $28(46.0 \%)$ & .value \\
\hline
\end{tabular}

${ }^{a}$ Statistically significant difference $(P<0.05)$ (Chi-square test)

Table 6. Correlation of balancing side occlusal contacts and bruxism

\begin{tabular}{|c|c|c|c|c|c|}
\hline & & \multicolumn{2}{|c|}{ balancing side occlusal contacts } & \multirow{2}{*}{ Total } & \multirow{2}{*}{$P$-value } \\
\hline & & Yes & No & & \\
\hline \multirow{2}{*}{ Male } & Bruxers & 14 & 12 & 26 & \multirow{2}{*}{$0.254^{a}$} \\
\hline & Non-Bruxers & 20 & 27 & 47 & \\
\hline \multirow{3}{*}{ Female } & Bruxers & 6 & 7 & 13 & \multirow{3}{*}{$0.254^{\mathrm{a}}$} \\
\hline & Non-Bruxers & 8 & 6 & 14 & \\
\hline & Total & 48 & 52 & 100 & \\
\hline
\end{tabular}

${ }^{a}$ Statistically significant difference $(P<0.05)$ (Chi-square test)

Table 7. Comparison occlusion patterns between male and female

\begin{tabular}{lcccc}
\hline & Canine guidance & Group function & Unclassifiable patterns & $\chi^{2}(P)$ \\
\hline Male & $22(30.1 \%)$ & $43(58.9 \%)$ & $8(11.0 \%)$ & $7.854(0.023)^{\mathrm{a})}$ \\
Female & $8(29.6 \%)$ & $10(37.0 \%)$ & $9(33.3 \%)$ & \\
\hline
\end{tabular}

${ }^{a}$ Statistically significant difference $(P<0.05)($ Chi-square test $)$

균형측 교합접촉은 이갈이군에서 $51.2 \%$. 비이갈이군 에서 $46.0 \%$ 로 나타났다. 통계분석결과 이갈이와 균형측 교합접촉간의 상관관계는 존재하지 않았다(Table 5).

성별에 따른 이갈이 유무와 균형측 교합접촉간의 상관 관계에 대해 분석한 결과 남자와 여자 그룹 모두에서 이 갈이와 균형측 교합접촉간의 상관관계는 존재하지 않았 다(Table 6).
성별에 따른 측방유도양상 비교 결과는 남자 그룹 은 군기능 교합이 $58.9 \%$, 여자 그룹은 $37.0 \%$ 로 나타났 다(Table 7). 성별에 따른 균형측 교합접촉 비교는 남자 그룹의 균형측 교합접촉 $47.9 \%$, 여자 그룹이 교합접촉 $51.9 \%$ 로서 통계적으로 성별에 따른 균형측 교합접촉 유 무의 차이는 없었다(Table 8). 
Table 8. Comparison of occlusal contacts on balancing side between male and female

\begin{tabular}{lccc}
\hline & \multicolumn{2}{c}{$\begin{array}{c}\text { Balancing side } \\
\text { occlusal contacts }\end{array}$} & $\chi^{2}(P)$ \\
& Yes & No & \\
\hline Male & $35(47.9 \%)$ & $38(52.1 \%)$ & \multirow{2}{*}{$0.120(0.729)^{a}$} \\
Female & $14(51.9 \%)$ & $13(48.1 \%)$ & \\
\hline
\end{tabular}

${ }^{a}$ Statistically significant difference $(P<0.05)$ (Chi-square test)

\section{고찰}

과거 이갈이의 정의와 원인, 기전에 관한 다양한 연구 들이 진행되어 왔지만 명확한 결론이 내려지지 않고 있 다. 우선 이갈이의 정의에 대해서도 정확한 합의가 이뤄 지지가 않았다. 일반적으로는 밤에 잘 때 나타나는 이갈 이를 지칭하지만, 큰 범위에서는 주·야간에 나타나는 비 기능적인 행위를 모두 포함한다. ${ }^{1}$ 이갈이의 정의가 합의 되지 않는 상황에서 이갈이에 관한 다양한 논문들의 이 갈이 진단기준, 유형, 연구방법 등이 모두 다르기 때문에 효과적인 결론을 내기가 어렵다.

이갈이 연구의 또 다른 어려움은 이갈이 진단이다. 자 각하기가 어려운 이갈이는 짧은 시간동안만 지속되며 간 헐적으로 나타나는 특성 때문에 부부간에도 인식하지 못 하는 경우도 있다. 설문을 이용하는 방법은 비용이 적게 들고 간편하다는 장점이 있지만 본인이 이갈이를 자각하 기 어려운 특성상 실제보다 유병률이 작게 나타날 수 있 다. ${ }^{17}$ 반면에 치아 마모면 평가에 의한 방법은 마모의 원 인이 이갈이 외에 다른 요인들도 있을 수 있기 때문에 실 제보다 유병률이 높게 나타날 가능성이 높다. ${ }^{18}$ 이갈이의 정확한 진단을 위해서는 저작근의 활성도를 기록하는 근 전도 검사(electromyography) 또는 수면패턴을 기록하는 수면다원 검사(polysomnography)를 이용해야 한다. 실 제 임상에서는 비용 및 시간적인 면에서 적용하는데 어려 움이 있으므로 일반적으로 임상적 이갈이의 증상 및 징 후가 존재하는지 여부를 간접적으로 검사한다. 먼저 인 터뷰나 설문지를 통해 조사를 하고 구강 내 검사를 통해 치아의 마모도와 파절, 치주 조직 등을 확인한다. 임상검 사 시 교근 비대양상이나 보철물의 마모 및 파절도 관찰 될 수 있다. 아침에 일어났을 때 통증 또는 개구제한이 있 는 경우 이갈이가 존재할 가능성이 높다.

교모 또한 다른 여러 원인으로 나타날 수 있으므로 유 의해야 한다. 1987 년 Woda 등 $^{19}$ 은 많은 교모면이 관찰
된다고 해서 이갈이가 있다고 보기는 어렵다고 하였고, 1994년 Kang과 $\operatorname{Han}^{20}$ 은 이갈이군과 비이갈이군에서의 교모 면적 및 교합접촉을 조사하였는데 이갈이군에서 교 모 면적이 다소 증가하는 경향은 있으나 통계적으로 유 의하진 않다고 하였다. 교모는 과거의 이갈이에 의해 발 생한 것으로 간주할 수 있지만 그것이 현재의 이갈이의 상태를 단정 짓는 것은 아니기 때문에 이갈이의 진단 기 준으로의 어려움이 있다.

이갈이의 진단은 한가지 기준이 아닌 여러 기준을 가지 고 복합적으로 이루어져야 한다. Lavigne와 Montplaisir ${ }^{21}$ 은 1995년에 이갈이 진단의 기준으로 1) 같은 실내에서 6 개월 이상, 주 5일 이상의 이갈이 소리 확인 2) 교모, 수복 물의 shiny spot, 기상 시 저작근의 피로감 및 통증, 교근 비대 중 1 개 이상 존재하여야 한다고 하였고 심한 이갈이 는 1) 이갈이를 1 시간에 4회 이상 확인 2) 이갈이 검사 시 이갈이 소리가 2회 이상 확인될 경우로 기준을 제시하였 다. 2005년 미국수면장애협회(American Sleep Disorders Association; ASDA)에서는 이갈이의 진단 기준을 제시 하였다. ${ }^{16}$ 이갈이를 진단할 시 이갈이의 활성도 및 중증 도, 발생기간 등을 종합적으로 평가하여 향후 치료 필요 여부를 결정해야 한다. ${ }^{22}$

측방유도에 대한 기존의 연구들을 보면 Beyron ${ }^{23}$ 은 유럽인에서 군기능 교합이 정상적인 형태라고 하였고, Weinberg $^{24}$ 는 군기능 교합 $81 \%$, 견치 유도 교합이 $19 \%$ 라 하였다. 이에 반해 Scaife 등 ${ }^{25}$ 은 견치 유도 교합이 주 로 나타나고 군기능 교합은 $26.6 \%$ 만을 차지한다고 하 였다. 본 실험에서는 측방유도검사 결과 이갈이가 있을 경우 군기능 교합 $61.5 \%$, 이갈이가 없을 경우 군기능 교 합 $47.5 \%$ 로서 두 그룹 모두 군기능 교합이 모두 높게 나 왔다. 이갈이가 있을 경우, 이갈이가 없는 경우와 비교하 여 군기능 교합이 나타날 확률이 통계적으로 유의하게 높다. 이는 이갈이에 의한 치아의 마모와 연관이 있을 것 으로 생각된다. 측방유도양상이 연령이나 치아의 마모 와 관련이 있는지에 대한 연구에서 Scaife와 $\mathrm{Holt}^{25}$ 는 견 치 유도 교합 그룹에서는 외견상 드러나는 치아의 마모 면이 대상자의 $13.8 \%$ 만 나타났으나 군기능 교합 그룹에 서는 $52.8 \%$ 에서 관찰되었다고 하였다. 즉, 견치 유도 교 합 보다 군기능 교합에서 치아 마모면이 더 많이 관찰되 었다. 본 실험에서, 이갈이 환자의 경우 이갈이로 인한 치 아의 마모 때문에 군기능 교합이 더 높게 나왔을 것이라 생각된다. 이갈이에 대한 고려 없이 성별 차이에 따른 측 방유도양상을 비교해 밨을 때 남성 그룹은 군기능 교합 
$58.9 \%$, 견치 유도 교합 $30.1 \%$, 기타 $11.0 \%$, 여성 그룹은 군기능 교합 $37.0 \%$, 견치 유도 교합 $29.6 \%$, 기타 $9 \%$ 로 나타났다. 통계적으로 남성 그룹에서 군기능 교합이 유의 하게 높게 나온 것 역시 성별에 따른 교합력의 차이로 인 한 마모의 영향으로 생각할 수 있다. 1993년 Dahl 등 ${ }^{26}$ 의 연구에서 여성보다 남성에게서 치아 마모가 더 많이 발 현되고 정도가 심한 이유를 보다 큰 교합력 때문으로 설 명하고 있다.

본 연구에서 균형측 교합접촉이 이갈이 환자의 $51.2 \%$, 비이갈이 환자의 $46 \%$ 에서 나타났다. 전체 100 명중에 48 명에서 균형측 교합접촉이 나타났다. 통계적으로 이갈이 와 균형측 교합접촉간의 상관관계는 나타나지 않았다. 균형측 교합접촉에 대한 과거의 연구를 살펴보면 Agerberg와 Sandström ${ }^{27}$ 은 성인의 약 $25 \%$ 에서 균형측 교합접 촉이 나타난다 하였고, Laat와 Steenberghe ${ }^{28}$ 의 연구에서 는 $61 \%$, Sadowsky와 BeGole ${ }^{29}$ 의 연구에서는 약 $90 \%$ 에 서 관찰된다고 하였다. 이와 같이 연구마다 다양한 결과 가 나타난 이유는 측방운동범위의 차이와 교합접촉 검사 방법의 차이 및 대상자의 연령 다양성에 따른 것으로 생 각된다. Ramfjord ${ }^{12}$ 는 균형측 교합접촉이 근기능에 장애 를 일으킨다고 하였고. Schuyler ${ }^{30}$ 의 연구에서는 균형측 교합접촉이 외상성 교합으로 작용한다고 하였다. Mohlin 와 $\mathrm{Kopp}^{31}$ 은 측두하악장애가 있는 사람에게서 균형측 교 합접촉이 더 많이 나타난다고 하였다. 그에 반해 Okeson 등 $^{32}$ 은 균형측 교합간섭은 습관에 의해서도 형성될 수 있 다 하였고, Drouka 등 ${ }^{33}$ 은 측두하악장애와 균형측 교합 접촉간의 상관관계는 없다고 하였다.

이갈이와 교합과 관련된 과거의 연구에서는 교두감합 위와 조기접촉, 교두감합위와 후방교합위의 불일치, 균 형측의 교두간섭 등이 이갈이의 유발인자로서 거론되기 도 하였으나, 이후의 연구들에서 상호 연관관계가 원인 인지 결과인지 확실하지가 않고 교합이상의 작용기전 이 명확히 설명되어 있지 않다는 비판적인 의견들이 제시 되었다. $\mathrm{Yemm}^{34}$ 의 연구에서 교합이상이나 조기접촉이 clenching이나 grinding을 일으켰다는 실험적 증거는 없 으며 신경생리학적으로 오히려 치아의 기계적 자극은 폐 구근의 활동을 감소 또는 억제시키는 효과가 있다고 하 였다. Bailey와 Rugh, ${ }^{35}$ Kardachi 등 ${ }^{36}$ 의 연구에서는 실험 적인 교합간섭을 부여하더라도 수면 중 교근의 활동은 저하되지 않았다. 본 실험에서도 과거의 연구결과와 같이 이갈이와 균형측 교합간섭의 상관관계를 분석한 결과 통 계적으로 유의성이 없었다.
성별에 따른 이갈이 유병률 분석에서는 통계적으로 남 녀 간에 차이가 없는 것으로 나타나 1997년 Attanasio ${ }^{5}$ 의 연구 결과와 동일하게 나타났다.

본 연구에서는 이갈이군의 수가 많지 않은 한계가 있 다. 이갈이로 유발된 마모로 인한 교합 요소를 평가하기 위해서는 보다 다양한 연령대와 중증도 이상의 마모를 나타내는 이갈이 환자를 대상으로 추가적인 실험이 필요 하다. 그리고 정확한 이갈이 진단을 위해서는 근전도 검 사 또는 수면다원 검사를 이용하여 심층적인 연구를 진 행하는 것이 필요하다.

\section{결론}

이갈이와 편심위 교합간섭의 상관관계 분석 결과 다음 과 같은 결과들을 얻었다.

1. 이갈이와 균형측 교합접촉간의 유의한 상관관계는 나타나지 않았다.

2. 균형측 교합접촉은 전체의 약 $48 \%$ 에서 나타났다.

3. 이갈이가 있는 경우에는 측방편심위유도 양상이 군 기능 교합으로 우세하게 나타났다.

4. 성별에 따른 이갈이 유병률의 차이는 없었다.

5. 성별에 따른 균형측 교합접촉 빈도의 차이는 없었다.

6. 남자일수록 군기능 교합이 높게 나타났다..

\section{Achnowledgments}

이 논문은 2017학년도 조선대학교 학술연구비의 지원 을 받아 연구되었음.

\section{References}

1. Okeson JP. Orofacial pain: guidelines for assessment, diagnosis, and management. 3rd. Chicago; Quintessence; 1996.

2. The glossary of prosthodontic terms. J Prosthet Dent 2005;94:10-92.

3. Diagnostic classification steering committee. Thorpy MJ. International classification of sleep disorders: diagnostic and coding manual. Rochester; American Sleep Disorders Assoiation; 1990.

4. Lavigne GJ, Montplaisir JY. Restless legs syndrome and sleep bruxism: prevalence and association among Canadians. Sleep 1994;17:739-43. 
5. Attanasio R. An overview of bruxism and its management. Dent Clin North Am 1997;41:229-41.

6. Clarke NG, Townsend GC, Carey SE. Bruxing patterns in man during sleep. J Oral Rehabil 1984;11: 123-7.

7. Rugh JD, Davis SE, Tiner BD. Feasibility of a laboratory model of nocturnal bruxism. J Dent Res 1991;70:554.

8. Cosme DC, Baldisserotto SM, Canabarro Sde A, Shinkai RS. Bruxism and voluntary maximal bite force in young dentate adults. Int J Prosthodont 2005;18:328-32.

9. Paesani DA. Bruxism: theory and practice. Berlin; Quintessence Publishing; 2010.

10. Bellini M, Marini I, Checchi V, Pelliccioni GA, Gatto MR. Self-assessed bruxism and phobic symptomatology. Minerva Stomatol 2011;60:93-103.

11. Pierce CJ, Chrisman K, Bennett ME, Close JM. Stress, anticipatory stress, and psychologic measures related to bruxsim. J Orofac Pain 1995;9:516.

12. Ramfjord SP. Bruxism, a clinical and electromyographic study. J Am Dent Assoc 1961;62:21-44.

13. Rugh JD, Barghi N, Drago CJ. Experimental occlusal discrepancies and noturnal bruxism. J Prosthet Dent 1984;51:548-53.

14. Kardachi BJ, Bailey JO, Ash MM. A comparison of biofeedback and occlusal adjustment on bruxism. J Periodontol 1978;49:367-72.

15. Safari A, Jowkar Z, Farzin M. Evaluation of the relationship between bruxism and premature occlusal contacts. J Contemp Dent Pract 2013;14:616-21.

16. American Academy of Sleep Medicine. International classification of sleep disorders. 3rd. Darien; American Academy of Sleep Medicine; 2014. p. 182-5.

17. Egemark-Eriksson I, Carlsson GE, Ingervall B. Prevalence of mandibular dysfunction and orofacial parafunction in 7-, 11- and 15-year-old Swedish children. Eur J Orthod 1981;3:163-72.

18. Seligman DA, Pullinger AG, Solberg WK. The prevalance of dental attrition and its association with factors of age, gender, occlusion, and TMJ symptomatology. J Dent Res 1988;67:1323-33.

19. Woda A, Gourdon AM, Faraj M. Occlusal contacts and tooth wear. J Prosthet Dent 1987;57:85-93.

20. Kang SS, Han KS. A study on the relation between occlusal wear and occlusal contact patterns. J Oral Med Pain 1994;19:153-68.

21. Lavigne GJ, Montplaisir JV. Bruxism: epidemiology, diagnosis, pathophysiology, and pharmacology. In: Fricton JR, Dubner R, editors. Orofacial pain and temporomandibular disorders: advances in pain research and therapy. New York; Raven Press; 1995. p. 387-404.

22. Michalowicz BS, Pihlstrom BL, Hodges JS, Bouchard TJ Jr. No heritability of temporomandibular joint signs and symptoms. J Dent Res 2000;79:1573-8.

23. Beyron HL. Occlusal changes in adult dentition. J Am Dent Assoc 1954;48:674-86.

24. Weinberg LA. A cinematic study of centric and eccentric occlusions. J Prosthet Dent 1964;14:290-3.

25. Scaife RR Jr., Holt JE. Natural occurrence of cuspid guidance. J Prosthet Dent 1969;22:225-9.

26. Dahl BL, Carlsson GE, Ekfeldt A. Occlusal wear of teeth and restorative materials. A review of classification, etiology, mechanisms of wear, and some aspects of restorative procedures. Acta Odontol Scand 1993;51:299-311.

27. Agerberg G, Sandström R. Frequency of occlusal interferences: a clinical study in teenagers and young adults. J Prosthet Dent 1988;59:212-7.

28. De Laat A, van Steenberghe D. Occlusal relationships and temporomandibular joint dysfunction. Part I: epidermiologic findings. J Prosthet Dent 1985;54:835-42.

29. Sadowsky C, BeGole EA. Long-term status of temporomandibular joint function and functional occlusion after orthodontic treatment. Am J Orthod 1980;78:201-12.

30. Schuyler CH. Factors contributing to traumatic occlusion. J Prosthet Dent 1961;11:708-15.

31. Mohlin B, Kopp S. A clinical study on the relationship between malocclusions, occlusal interferences and mandibular pain and dysfunction. Swed Dent J 1978;2:105-12.

32. Okeson JP, Dickson JL, Kemper JT. The influence of assisted mandibular movement on the incidence of nonworking tooth contact. J Prosthet Dent 1982;48:174-7. 
33. Droukas B, Lindee C, Carlsson GE. Occlusion and mandibular dysfunction: a clinical study of patients referred for functional disturbances of the masticatory system. J Prosthet Dent 1985;53:402-6.

34. Yemm R. Neurophysiologic studies of temporomandibular joint dysfunction. Oral Sci Rev 1976;7: 31-53.

35. Bailey JO, Rugh JD. Effect of occlusal adjustment on bruxism as monitored by nocturnal EMG recordings. J Dent Res 1981;46:241.

36. Kardachi BJ, Bailey JO, Ash MM. A comparison of biofeedback and occlusal adjustment on bruxism. J Periodontol 1978;49:367-72. 


\section{이갈이와 편심위 교합간섭의 상관관계 분석}

\section{이호선, 김미경, 진수윤, 김희중, 이경제*}

조선대학교 치과대학 치과보철학교실

목적: 이갈이와 편심위 유도양상 및 균형측 교합간섭과의 연관성에 대해 분석해 보고자 한다.

연구 재료 및 방법: 이갈이와 비이갈이군 및 성별에 따른 군기능 교합 및 균형측 교합간섭의 차이를 비교하고 편심위 유 도 양상 및 이갈이와 균형측 교합간섭간의 상관성을 알아보기 위해 제 3 대구치를 제외한 상실치가 없는 26 - 37세 사이의 100 명의 유치악 성인(이갈이군 39명, 비이갈이군 61명)을 대상으로 실험을 하였다. 디지털 교합분석장치 T-Scan system 을 이용하여 최대교두감합위, 좌·우측방 편심위 운동을 측정하여 균형측 교합접촉의 유무를 판별하였으며 각 대상의 편 심위 교합유도 양상에 대해서도 측정하였다. 디지털 교합분석 장치 검사 후 교합지를 이용하여 접촉되는 치아를 재확인 하였다.

결과: 군기능 교합이 이갈이군에서 $61.5 \%$, 비이갈이군에서 $47.5 \%$ 로 가장 높게 나타났다. 남자는 군기능 교합이 $58.9 \%$, 여자는 $37.0 \%$ 로 나타났다. 균형측 교합접촉은 전체 100 명 중 48 명에서 나타났고 이갈이군에서는 $51.2 \%$, 비이갈이군에 서는 $46 \%$ 였다. 통계적으로 이갈이와 균형측 교합접촉간의 유의성은 나타나지 않았다. 성별에 따른 균형측 교합접촉의 차이도 없었다.

결론: 이갈이와 균형측 교합 접촉간에는 상관관계가 없었다. 이갈이군에서 군기능 교합이 가장 높게 나타났다. (구강회 복응용과학지 2018;34(4):253-61)

주요어: 이갈이; 균형측 교합간섭; 견치 유도 교합; 군기능 교합; T-Scan system 